Author's post-print: Mar Alonso Martínez, Juan José del Coz Díaz, Antonio Navarro Manso and Daniel Castro Fresno. "Bridge-structure interaction analysis of a new bidirectional and continuous launching bridge mechanism" Engineering Structures 59 (2014) 298-307. http://dx.doi.org/10.1016/j.engstruct.2013.10.039

\title{
Bridge-structure interaction analysis of a new bidirectional and continuous launching bridge mechanism
}

\author{
Mar Alonso Martínez ${ }^{1}$, Juan José del Coz Díaz ${ }^{2 *}$ Antonio Navarro Manso ${ }^{3}$ and \\ Daniel Castro Fresno ${ }^{1}$
}

${ }^{1}$ GITECO Research Group, ETSICCP, University of Cantabria, 39005 Santander (Spain)

${ }^{2}$ Department of Construction, EPI Gijón, University of Oviedo, 33204 Gijón (Spain)

${ }^{3}$ Department of Energy, EPI Gijón, University of Oviedo, 33204 Gijón (Spain)

\section{Introduction}

Incremental launching is an inexpensive and useful technique to erect bridge structures. This method is based on pushing the bridge structure using several devices which provide the friction force needed to move the bridge. This method has been applied since the nineteenth century in Europe and it is currently very widely used around the world [1]-[2]: Bridge over the Caroni River (Venezuela); Bridge over the Danube river (Müller, Austria); Bruggen Viaduct over the Sitter river (Switzerland); Vaux Viaduct between Lausanne and Bern (Switzerland), and so on. Initially, the friction-based launching method was only used for concrete structures, due to the high normal load provided. However, steel structures can currently be launched by friction [3][4]. Some of the most important bridges in the world were made using this technique, such as the Millau Viaduct in France, which was built from 2001 to 2004, or the "Arroyo Las Piedras viaduct", the first composite steel-concrete high-speed railway bridge built in Spain [5]. Although this technique is very widely used, it has several disadvantages which must be overcome in order to improve constructions methods [6]-[7].

An important problem in ILM is the local stress in the cross section which gives rise to the patch loading phenomenon. This structural local failure is the most important effect in the case of steel bridges and it is an important research line currently [8]-[10]. The normal load on the launching

\footnotetext{
${ }^{*}$ Corresponding Author: Prof. Juan José del Coz Díaz

Edificio Dep. Viesques 7, despacho 7.1.02 - Gijón - 33204 (SPAIN)

Email: Juanjo@,constru.uniovi.es (+34-985182042)
} 
devices is not distributed and uniform, so the normal reaction exerts a local force in the bridge structure which can cause the collapse of the bridge. Previous authors studied the non-uniform distribution of bearing stress on a launching shoe [11].In that study the authors developed an analytical model which describes the distribution of the support's reaction. They demonstrated that the normal load applied on the launching shoe is a concentrated load in the center of the launching shoe instead of being a uniform distribution of reaction over the whole load-bearing surface. Other authors studied strategies for analysis of construction stages, showing the internal stress redistribution due to restrained creep [10].

Based on previous works, it is known that the interaction between the bridge and the launching devices is very important. This contact surface is very important in order to ensure the correct launching using the friction force. In this sense, this paper presents a numerical study of the structural interaction between a bridge and a new device to launch structures by friction force [12]. This paper provides a valuable contribution to the civil engineering field focused on a new method for launching bridges by a continuous and bidirectional mechanism. The structural interaction between the bridge and the mechanism which pushes the bridge is studied by numerical methods following the process utilized in other research works in which these methods were used successfully [13]-[14].

The authors of this paper have worked in a new design to launch bridges using friction force. This new design improves the current methods, obtaining a new procedure that is more efficient, economical and safe. The current methods of launching bridges need several hydraulic jacks to place the bridge in its final position [3]-[4],[7]. Vertical and horizontal launching jacks move the bridge using the force of friction as is shown in Fig. 1. The procedure of launching the bridge using this system is as follows: first, the vertical jacks provide the necessary force between the mechanism and the bridge, then horizontal jacks move the bridge structure forward. In order to induce the displacement by friction force, a surface contact is necessary between the bridge and the launching device. Pushing the bridges is a frequently used technique in spite of several problems. This research group has worked on this method for years in order to improve launching safety, as well as to decrease the operation time and to achieve higher average speed in the launching process.

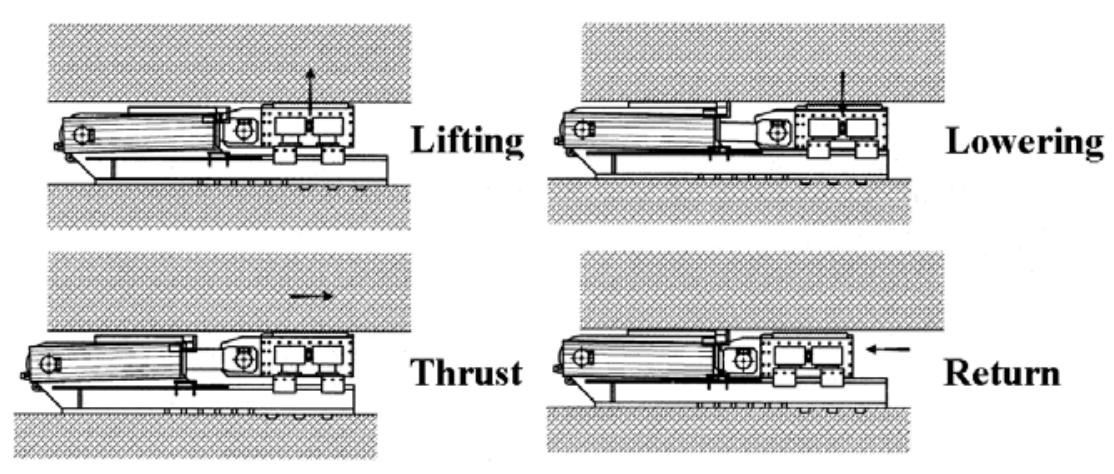


Fig. 1. Operating principle of the hydraulic jacks in bridge launching.

There are some shortcomings in the current launching method [3],[7],[15]:

- Auxiliary systems are needed in order to control the launch and make sure it is safe.

- The average speed of launching is low because the current mechanisms work at very low speed.

- The method is discontinuous due to the retraction of the launching jacks. For this reason, there is a lot of dead time which are inefficient.

- The current method is unidirectional because the structure only pushes forward. Backward displacement is obtained using other auxiliary systems. For this reason, the launching procedure is slow and expensive when backward displacement is required.

For these reasons, the study of the structural interaction between the bridge and the launching mechanism is a very important research line to avoid problems during the launching procedure [10-11]. It is very useful to analyze the adaptation of the new launching device to the deformed shape of the bridge structure when this is being built. Furthermore, the concentrated load in the steel webs of the bridge during the launching process is an important problem in the current launching methods. The new launching device developed in this innovative paper improves the web's behavior under patch loading effects because the normal reaction is distributed among several support links.

In summary, the statement of the problem is based on the current limitations of bridge launching procedures and the research significance is demonstrated by means of the development of a new mechanism for continuous launching of heavy structures.

\section{DCACLM for heavy structure displacement}

In order to improve the launching method, a new device able to provide a continuous and bidirectional displacement has been designed. This system pushes the superstructure using the force of friction. This new device was patented by the authors of this paper in 2011 (WO 2013/001114A1) [12]. This patent is referred to in this paper as DCACLM.

Two design factors were taken into account:

- The bidirectional and continuous displacement.

- The high normal load which has to be supported. 
The DCACLM device pushes the bridge structure both bidirectionally and continuously. The design of this device is based on an inverted crawler which can move in two directions, forward and backward. Furthermore, the track-crawling have the ability to adjust their components to the terrain in order to increase adherence. Another important requirement of the mechanism is to support high normal loads due to the dead weight during the launching process. The DCACLM device can launch the structure by force of friction from a fixed point on the abutment [16][17].

The device consists of several chains joined together by bolts whose links have a specially designed geometry to support the normal load (see Fig. 2). Furthermore, there are two transmission chains which are used for transmitting mechanical power generated by a couple of engines which activate several gear wheels. These sprockets move the transmission chains. In this way, continuous and bidirectional movement is possible.
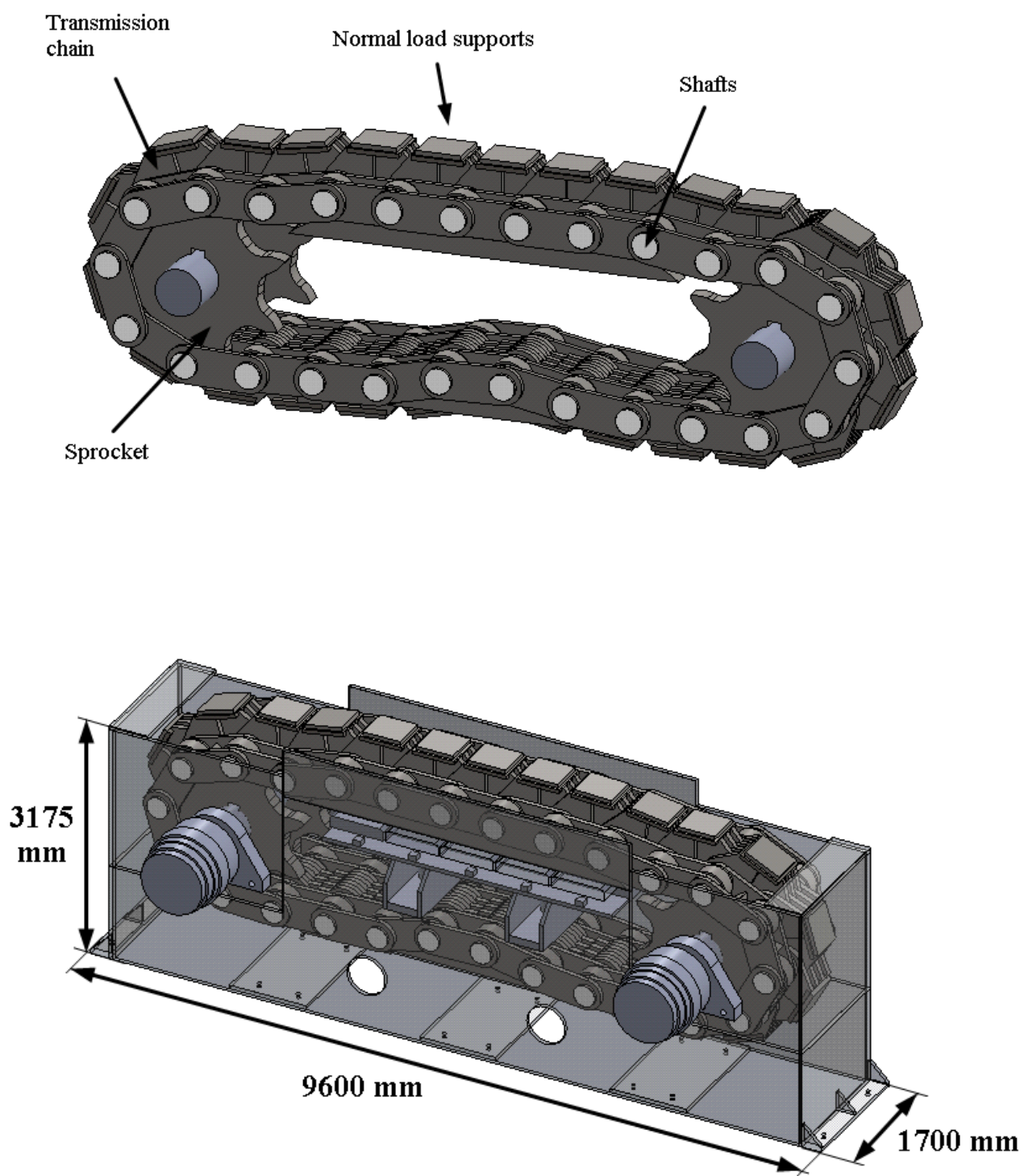
Fig. 2. Mechanism based on terra mechanism vehicles: main elements (above) and overall view with main dimensions (below).

\subsection{The problem of structural interaction in the launching method}

The new device studied in this paper provides a new construction system to displace heavy structures in a continuous and bidirectional way. This device was designed as a new system to construct bridges. This new system of construction consists of launching bridges with spans greater than $120 \mathrm{~m}$. without auxiliary systems. This system is more efficient than current systems. Higher speed is achieved using the new DCACLM device, as well as greater safety and better load control during the launching, and the environmental effects of civil constructions are reduced due to the decrease in the use of auxiliary systems. Despite the advantages, there are some drawbacks with the use of the new DCACLM system. One of the most important is the contact surface between the bridge structure and the launching mechanism. This contact surface is needed to achieve the friction force which induces the bridge displacement. The DCACLM device is placed under the bridge structure as Fig. 3 shows.

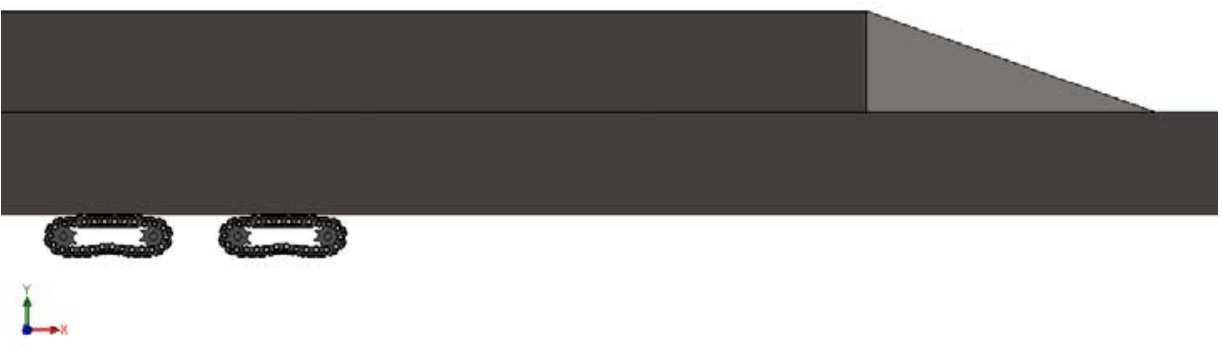

Fig. 3. Bridge structure over the new launching device.

Previous studies related to steel bridge launching led to significant observations that had to be taken into account in the new DCACLM launching device. These considerations are mainly to do with the non-uniform distribution of loads in the launching shoe [11] and other internal effects on the bridge structure [10],[14],[18]. Several experimental tests show two effects which are also disadvantages for the new DCACLM device. First, the load distribution and the girder curvature were tested and it was found that the geometrical imperfections affect the reaction distribution. Second, horizontal friction tests show that the coefficient of friction varies depending on the stress distribution on the launching jacks. The different values of the vertical load affect the horizontal launching force. In this sense, the new DCACLM device suffers these problems during the launching process due to the non-uniform distribution of the normal load over the support links. 
The load distribution and the structural interaction between the structure and the DCACLM device is studied in this research paper using numerical modeling.

\subsection{Description of the strategy}

The finite element method is a powerful tool to study structural analysis. The sub-structuring technique is an advanced tool that is used to study the structural interaction between the bridge and the DCACLM device. The sub-structuring technique is also very useful for many kinds of structural analysis [19]-[20]. The main objective of this technique is to reduce two complex, nonlinear problems to an efficient numerical model. In this way, it is possible to study two non linear numerical models and their interaction while reducing computational time and resources. The non-linear numerical model of the bridge structure has more than 500,000 Degrees of Freedom (DOF) and the non-linear model of the launching mechanism has more than 400,000 DOF. However, the combination of them using the sub-structuring technique is 303,541 which is less than half of the other two problems separately.

Sub-structuring is a technique that combines a group of finite elements into one element [21]. This element is represented by a matrix. In this way, it is possible to reduce a non linear numerical model to a simplified one to obtain a linear response.

In this case, the non linear numerical model of the bridge structure is reduced to one finite element which is called "superelement". The superelement has several nodes, called "master nodes", whose degrees of freedom (DOF) are set depending on the boundary conditions. The "master nodes" are needed to connect the superelement to the rest of the numerical model, in this case the new launching device. The global model of the structural interaction problem consists of the superelement, the numerical model of the launching device and the connection between them.

Several commercial programs can solve the sub-structuring problem, such as SAP, ABACUS or ANSYS. In this case, ANSYS was used to solve the structural interaction using a proprietary code written in Advanced Parametric Design Language (APDL) [22-23].

\section{Methodology of the numerical modeling using sub-structuring technique}

\subsection{Mathematical model}

The methodology applied in this paper is based on the substructuring technique which reduces a complex non linear model to a single superelement, which is the bridge structure in this case. 
$[K]\{u\}=\{F\}$

Where:

$\{F\}$ includes nodal, pressure and temperature effects.

The equations may be partitioned into two groups, the master (retained) DOFs, here denoted by the subscript " $m$ ", and the slave (removed) DOFs, here denoted by the subscript "s".

$$
\left[\begin{array}{l}
{\left[K_{m m}\right]\left[K_{m s}\right]} \\
{\left[K_{s m}\right]\left[K_{s s}\right]}
\end{array}\right]\left\{\begin{array}{l}
\left\{u_{m}\right\} \\
\left\{u_{s}\right\}
\end{array}\right\}=\left\{\begin{array}{l}
\left\{F_{m}\right\} \\
\left\{F_{s}\right\}
\end{array}\right\}
$$

Expanding the above system equations:

$$
\begin{aligned}
& {\left[K_{m m}\right]\left\{u_{m}\right\}+\left[K_{m s}\right]\left\{u_{s}\right\}=\left\{F_{m}\right\}} \\
& {\left[K_{s m}\right]\left\{u_{m}\right\}+\left[K_{s s}\right]\left\{u_{s}\right\}=\left\{F_{s}\right\}}
\end{aligned}
$$

The master DOFs should include all DOFs of all nodes on surfaces that connect to other parts of 


$$
\left\{u_{s}\right\}=\left[K_{s s}\right]^{-1}\left\{F_{s}\right\}-\left[K_{s s}\right]^{-1}\left[K_{s m}\right]\left\{u_{m}\right\}
$$

189 Substituting $\left\{u_{s}\right\}$ into equations (3):

$$
\left[\left[K_{m m}\right]-\left[K_{m s}\right]\left[K_{s s}\right]^{-1}\left[K_{s m}\right]\right]\left\{u_{m}\right\}=\left\{F_{m}\right\}-\left[K_{m s}\right]\left[K_{s s}\right]^{-1}\left\{F_{s}\right\}
$$

190

In the preceding development, the load vector for the superelement has been treated as a total load vector. The same derivation may be applied to any number of independent load vectors, which in turn may be individually scaled in the superelement use pass. For example, the analyst may wish to apply thermal, pressure, gravity, and other loading conditions in varying proportions. Expanding the right-hand sides of equations (3) and (4) gives, respectively [25]:

$$
\begin{aligned}
& \left\{F_{m}\right\}=\sum_{i=1}^{N}\left\{F_{m i}\right\} \\
& \left\{F_{s}\right\}=\sum_{i=1}^{N}\left\{F_{s i}\right\}
\end{aligned}
$$

\subsection{General strategy to study the structural interaction by sub-structuring technique}

The global numerical model consists of the superelement and the non-linear numerical model of the launching device. The numerical model of the bridge structure is reduced to an element, the superelement, whose nodes are called "master nodes". The degrees of freedom (DOF) of these master nodes are set to provide the normal load from the bridge structure to the new DCACLM device in the vertical direction. In order to obtain the global numerical model the following procedure based on the sub-structuring technique was developed:

1. Develop the simplified numerical model of the bridge structure. The numerical model of the bridge is reduced to a MATRIX50 element [22-23]. This has several nodes which provide the load transmission from the bridge to the new launching device. The boundary conditions of this element depend on the global boundary conditions.

2. Verification of the bridge structure superelement in a simple numerical problem. In this stage, the superelement is tested in known conditions in order to demonstrate the linear behavior of the simplified numerical model. In this case, the superelement is supported 


\subsection{Numerical model used}

The numerical model used to solve the structural interaction between the bridge structure and the new DCACLM device consists of three parts:

- Superelement of the bridge structure, see Fig. 4(a)

- Non linear model of the new DCACLM device, see Fig. 4(b)

- Connection between the superlement and the nonlinear model of the DCACLM, and total reaction of the global system, see Fig. 4(c)

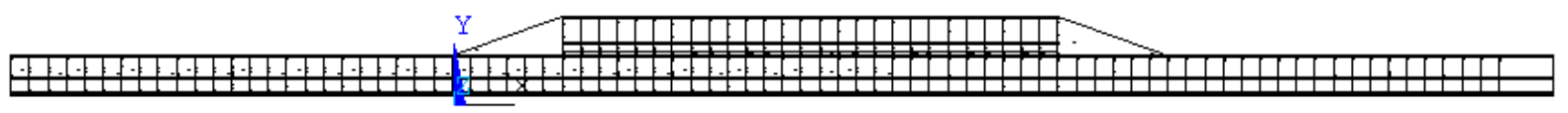




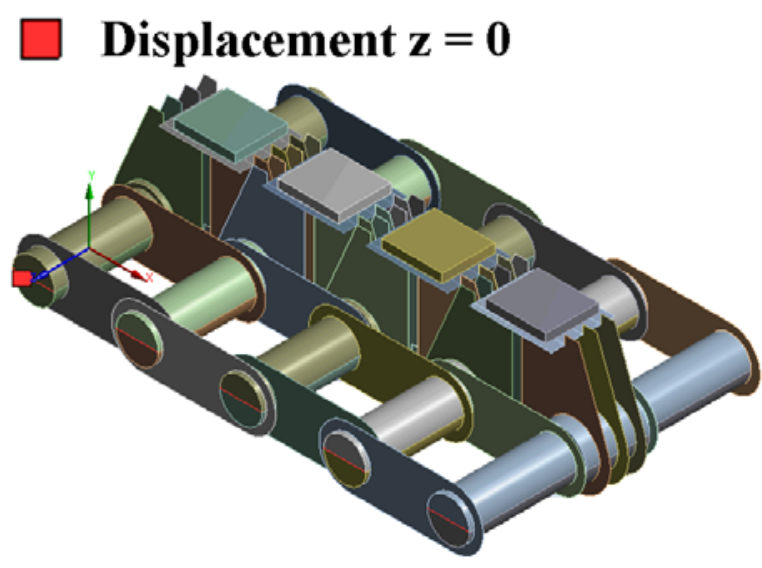

(b)

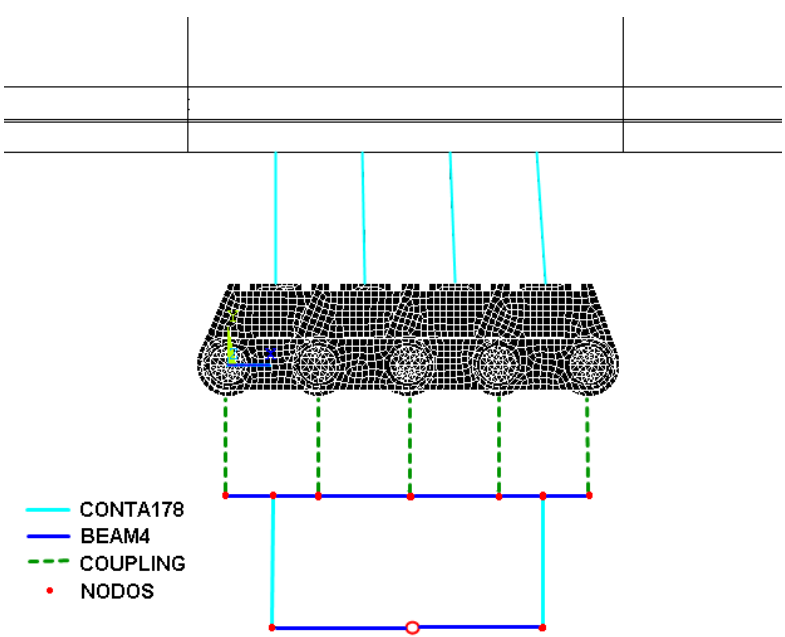

(c)

Fig. 4. Numerical models used: (a) superelement of the bridge structure; (b) simplified model of the launching device; (c) connections and total reaction supports.

The bridge structure is reduced to one element which has several "master nodes". All the master nodes allow the displacement of the structure in the vertical direction and are restricted in other directions. The boundary conditions of the superelement depend on the sequence of launching: at the beginning of the launching, one support is needed but, when the structure is near to the first pile, the support can be eliminated and the bridge is only supported by the new DCACLM device. The bridge provides the vertical load on sixteen support links of the DCACLM device during the different phases of the launching procedure. This load passes through the contact element, CONTA178 [22-23], and is applied on the center of the sheet of the support link as is shown in Fig. 4(c). The main properties of this nonlinear contact element are shown in Table 1.

Table 1. Properties of the non-linear contact element.

\begin{tabular}{cc}
\hline Parameter & Value \\
\hline Unidirectional gap, vertical direction \\
Pure penalty contact algorithm \\
Weak spring not used \\
FKN: Normal Stiffness \\
GAP: Initial gap size & 0.3 \\
START: Initial contact status & $1.284 \cdot 10^{7}$ \\
STArd behavior of contact surface, friction coefficient & 0 \\
FKS: Sticking stiffness in tangential direction for closed contact & Closed (1) \\
\hline
\end{tabular}


The reaction is distributed on the main resistant elements of the DCACLM device. There are two main boundary conditions of the global numerical model: on the one hand, the support of the bridge structure during the launching process if necessary; on the other hand, the support of the bolt ends which can restrict movement in the $\mathrm{Z}$ direction. Finally, the global system is supported on a group of finite elements that make it possible to obtain the total reaction of the global system. These additional finite element groups in the DCACLM device will be referred to as "system of load compensation" in this paper.

The system of load compensation is included in the global numerical model in order to obtain the total reaction. If this value is known, it will be possible to detect large differences in the load distribution. Furthermore, it will be possible to apply vertical loads from the new launching device to the bridge structure in order to adjust the shape. The numerical model of the system of load compensation is shown in Fig. 4(c). It consists of uniaxial finite elements which are known as BEAM4, two contact elements designed as CONTA178, which only transmit the vertical load, as well as a coupling configuration which associates the vertical displacement of the nodes from the bolts to the displacement of the nodes of the BEAM elements [22-23].

\section{Cases studies}

In bridge erections, specifically in large bridge constructions, the construction stages are usually as important as the service life. This is due to the stress distribution within the bridge structure and also other aspects such as the joints among the structure segments or the launching forces of the launching devices on the structure and so on. These problems in construction methods have been studied for years by other authors using non-linear numerical methods [11]-[10]. In this paper the most critical situation from the launching device point of view is near the first pile where the bridge structure has a very large deflection. In this paper, four stages around the first pile were studied in order to obtain the reaction force of the bridge structure.

Stage 1

Stage 2

Stage 3
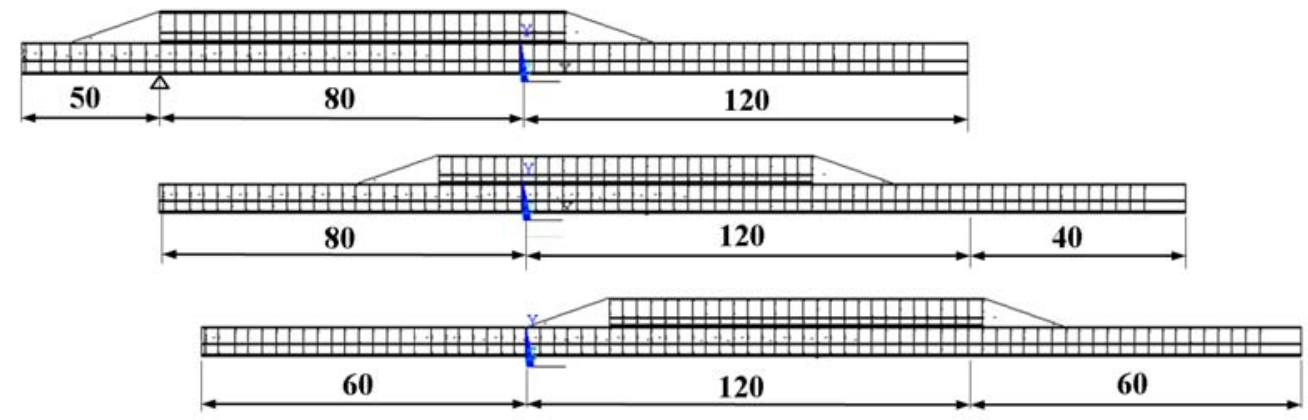

Stage 4

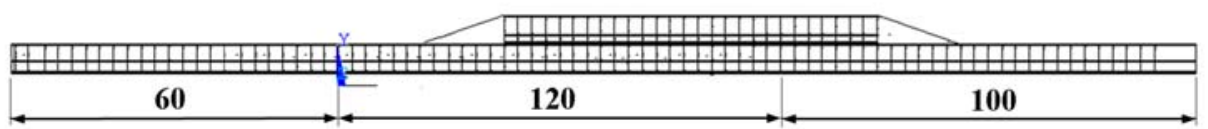

Fig. 5. Stage of launching process studied. 
The highest normal reaction on the new DCACLM device, which is placed in the abutment, was obtained in stage 1 when the bridge structure was close to the first pile. In this situation the reaction force on the launching device reaches its highest value. In this stage, two different aspects were studied by numerical simulation using the sub-structuring technique: first, the best arrangement for the new DCACLM launching device was studied in order to choose the best one; and second, the distribution of the load on the new DCACLM device was assessed for the previously chosen arrangement.

279 A detail of the numerical model used in all case studies is shown in Fig. 6.

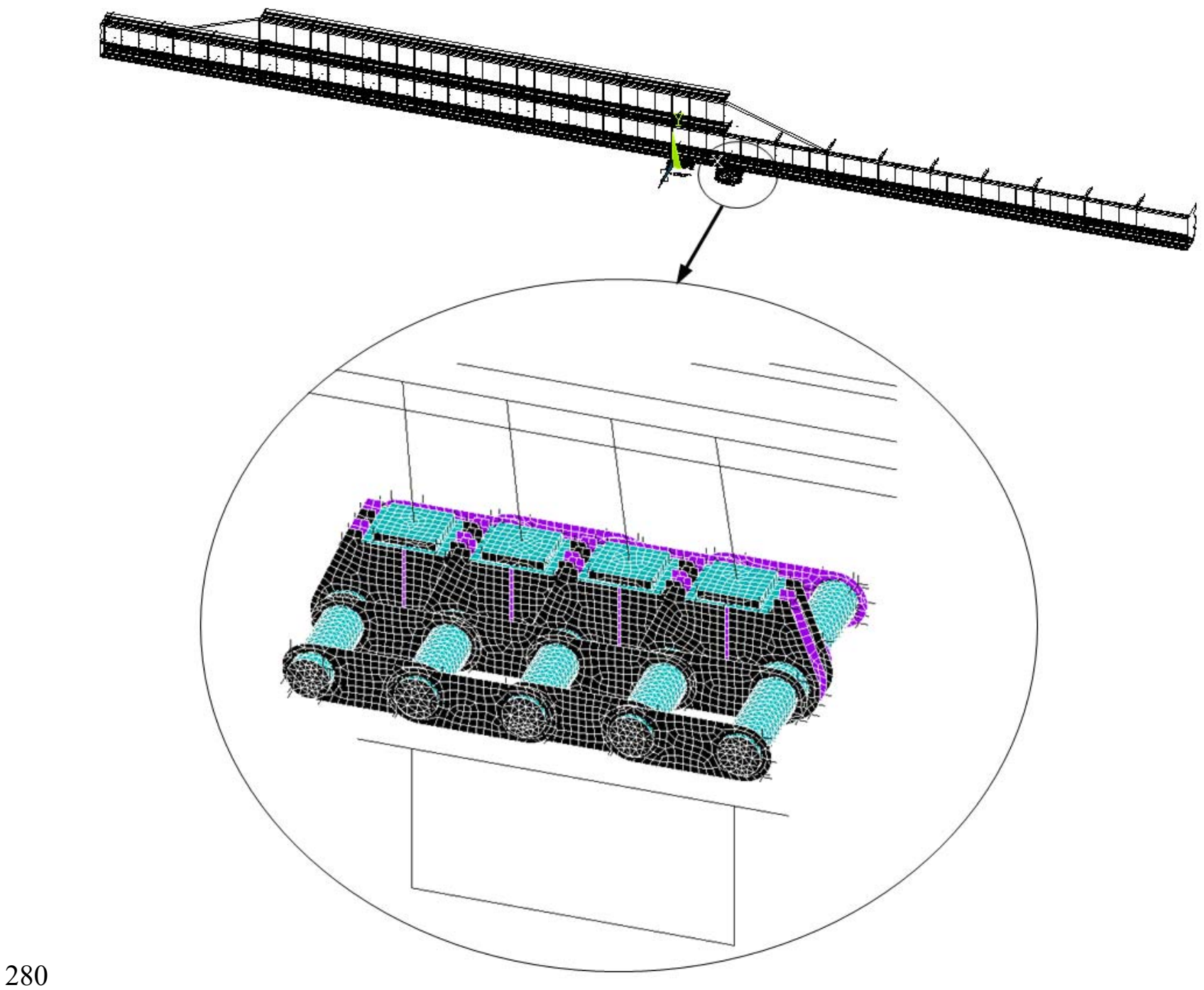

Fig. 6. Global numerical model used. 


\subsection{Linear and non-linear analyses}

299

The contact between the bridge structure and the DCACLM has been studied in two different cases. On the one hand, a bonded linear contact was simulated using coupled nodes in the vertical, $Y$ - direction. On the other hand, a nonlinear frictional contact was modeled using nonlinear finite elements named CONTA178 [22-23]. The main properties of this element are shown in Table 1.

In both cases the total reaction obtained is the same, $1.18 \cdot 10^{7} \mathrm{~N}$, which also takes into account the DCACLM dead load. However, the structural response is completely different. The results shown in Fig. 7. indicate stiffer behavior for the linear contact than for the non-linear contact. The force reaction in the prefabrication area for the linear numerical model is lower than in the case of the non-linear numerical model. This is due to the stiffness between the superelement and the DCACLM, where the linear coupling makes the joint stiffer than non-linear contact, which is not the real structural behavior. The real behavior is as a vertical support with a specific value of the coefficient of friction. The non-linear contact reproduces the real support more faithfully than the linear model. In this sense, it has been proved that the non-linear analysis simulates the real behavior more accurately than linear analysis.

\section{LINEAR SOLUTION}

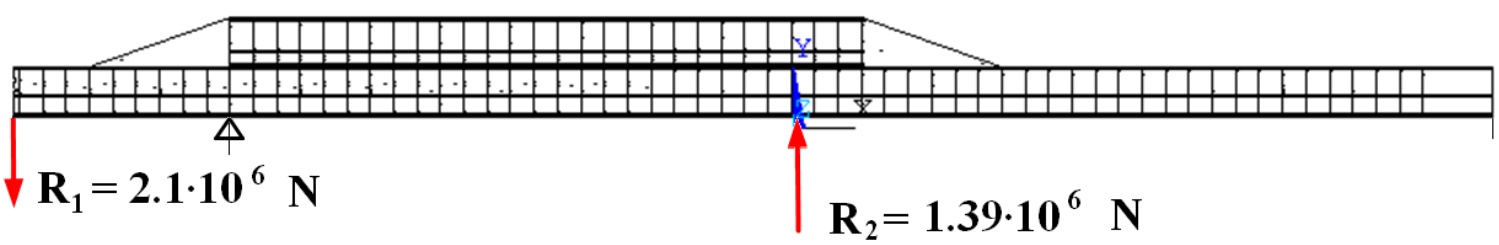

\section{NON-LINEAR SOLUTION}

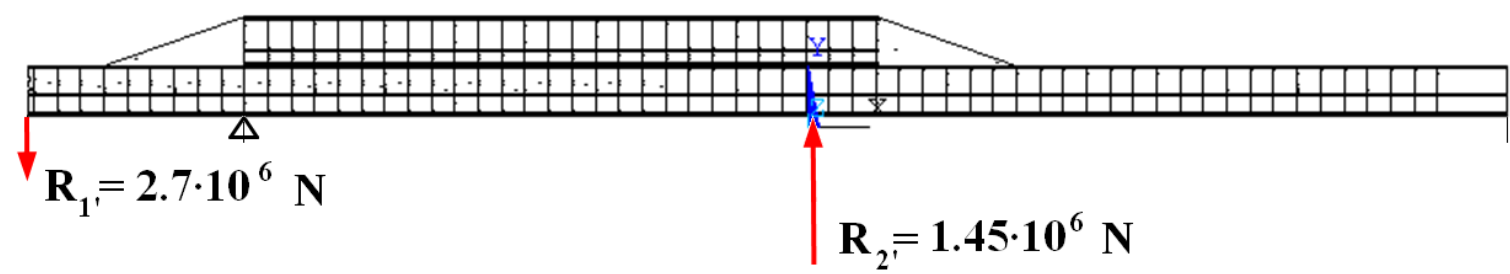

Fig. 7. Comparison of results between linear and non-linear analyses.

\subsection{The best arrangement}

Three different configurations were studied using the sub-structuring method: 

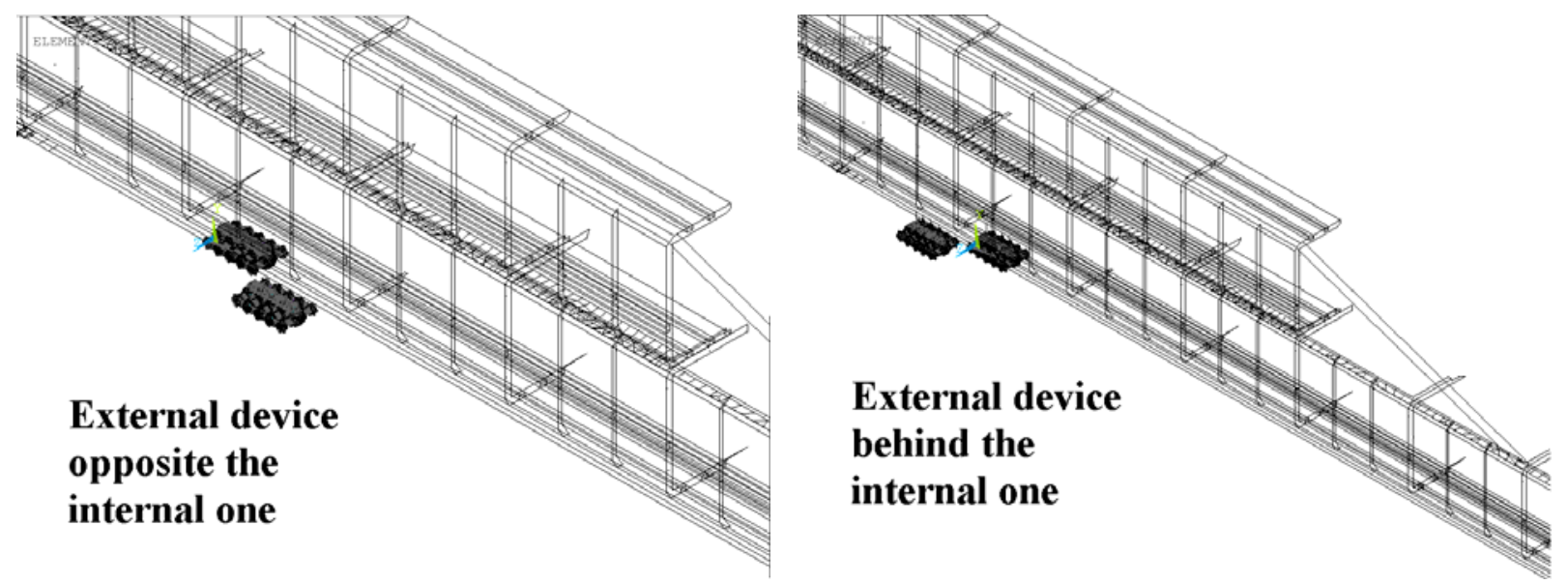

(a) (b)

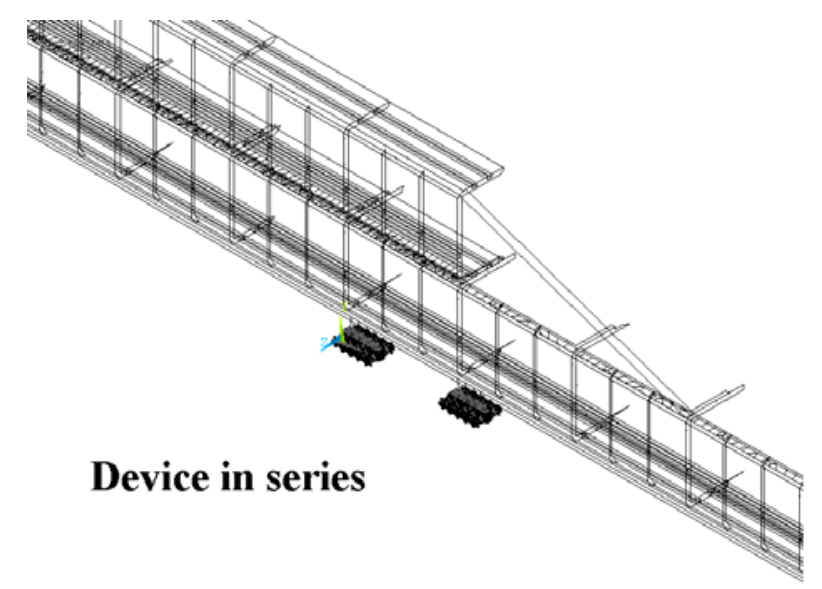

(c)

Fig. 8. Arrangements of the new DCACLM device studied.

309 These three different arrangements were studied in the first stage when $120 \mathrm{~m}$. of bridge are 310 launched and the reaction force in the abutment is at its highest value. In this sense, the results 311 obtained in the arrangements were compared. The best arrangement will be that whose maximum 312 reaction force has the lowest value. 
Taking into account the results obtained, the best arrangement of the new launching devices is in

314 series, see Fig. 8(c). If there are two launching devices in series under the webs of the bridge the 315 reaction value is lower than in the other cases studied. The results of the total reaction in the new 316 DCACLM device obtained by numerical methods using the sub-structuring technique are shown 317 in Fig. 8.

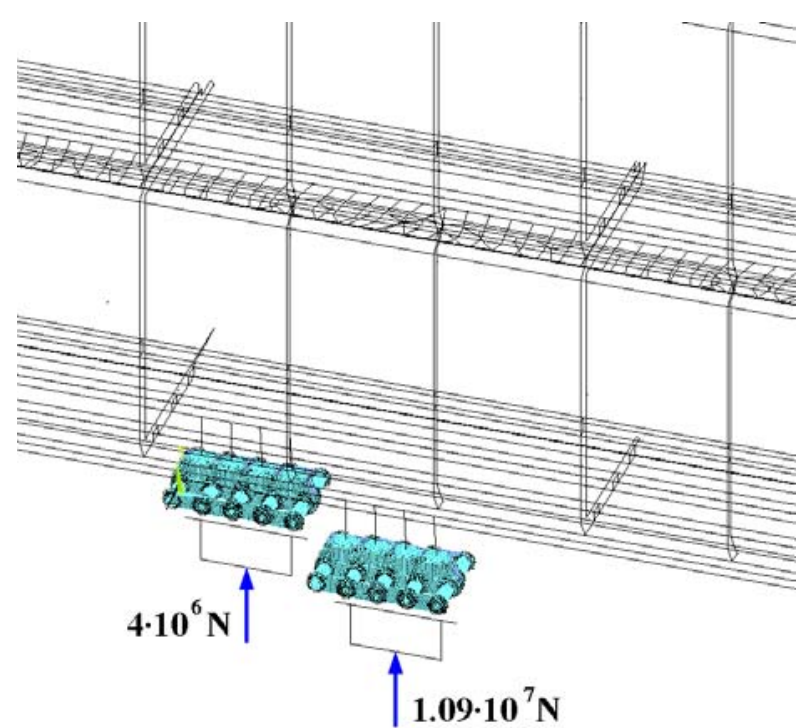

(a)

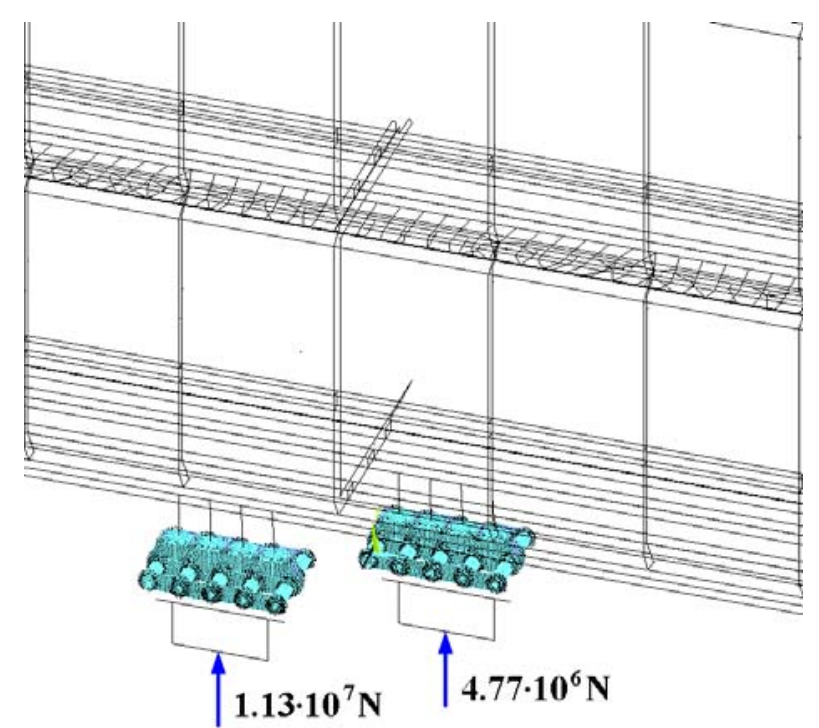

(b)

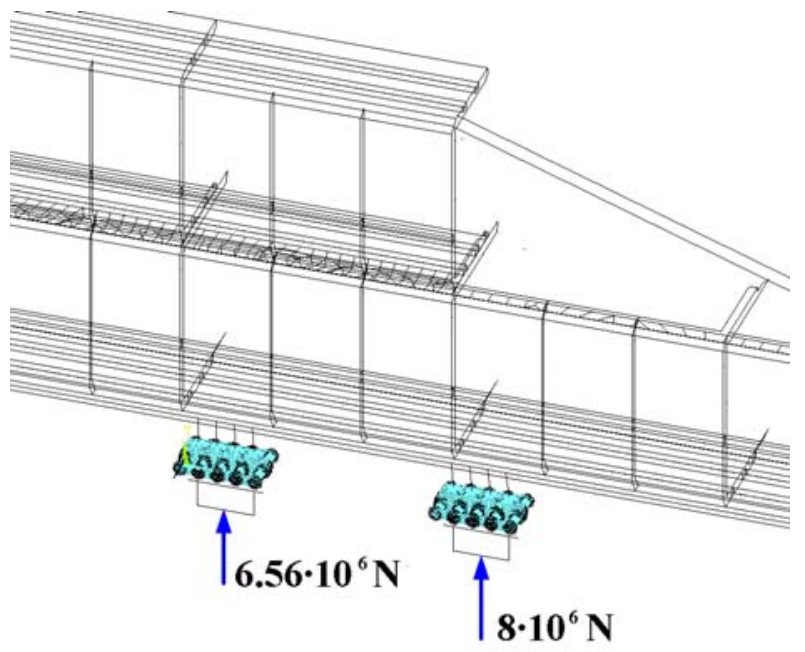

(b)

Fig. 9. Total reaction of the DCACLM launching device for the three arrangements. 


\subsection{The non uniform distribution of the load}

321 When the best arrangement was selected, the distribution of the normal load over the launching

322 device was studied. In all cases, four support links were considered to be the bearings of the 323 structure.

324 The superelement transmits the normal load to the launching device through contact elements, 325 named CONTA178 [22]-[23]. Each master node is joined to the center of the support plate in the 326 support link. The vertical load is applied at this point. It was proved that the total normal load is 327 non-uniformly distributed over the four supports.

328 The results obtained for the most critical launching phase are shown in Fig. 10.

\section{$120 \mathrm{~m}$. of bridge launched}

\section{Launching direction}

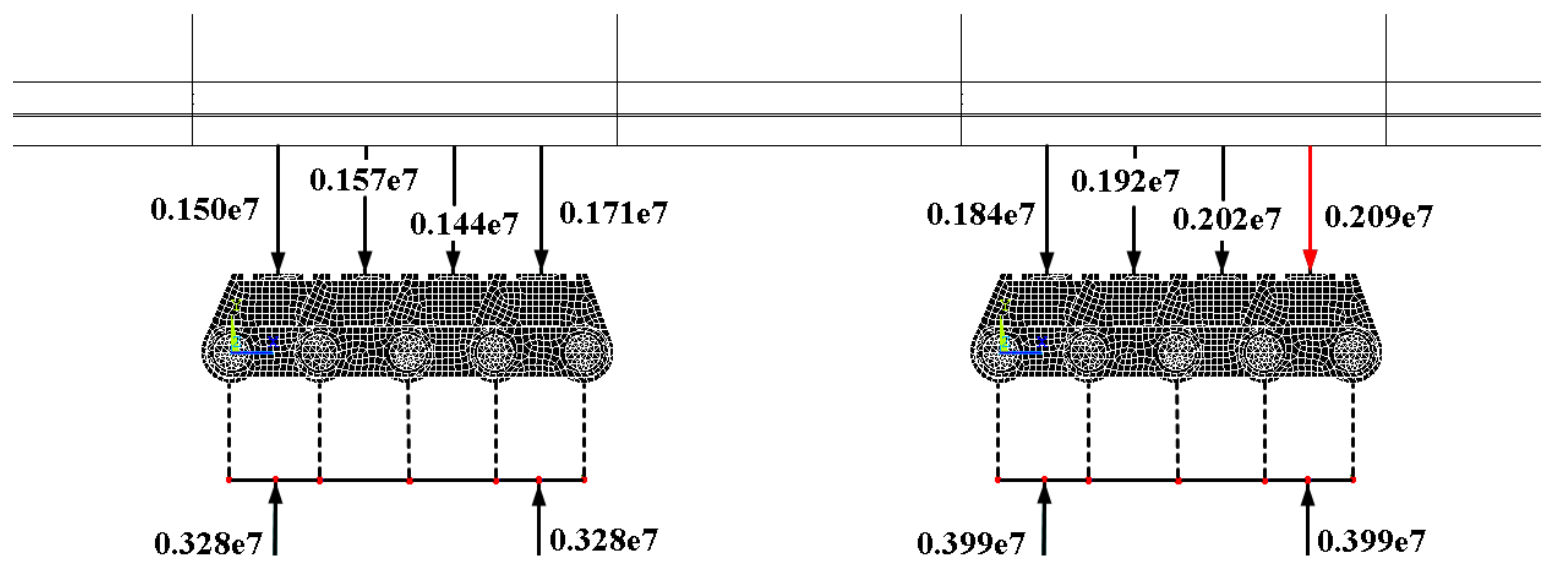

(a) 
$160 \mathrm{~m}$. of bridge launched

Launching direction

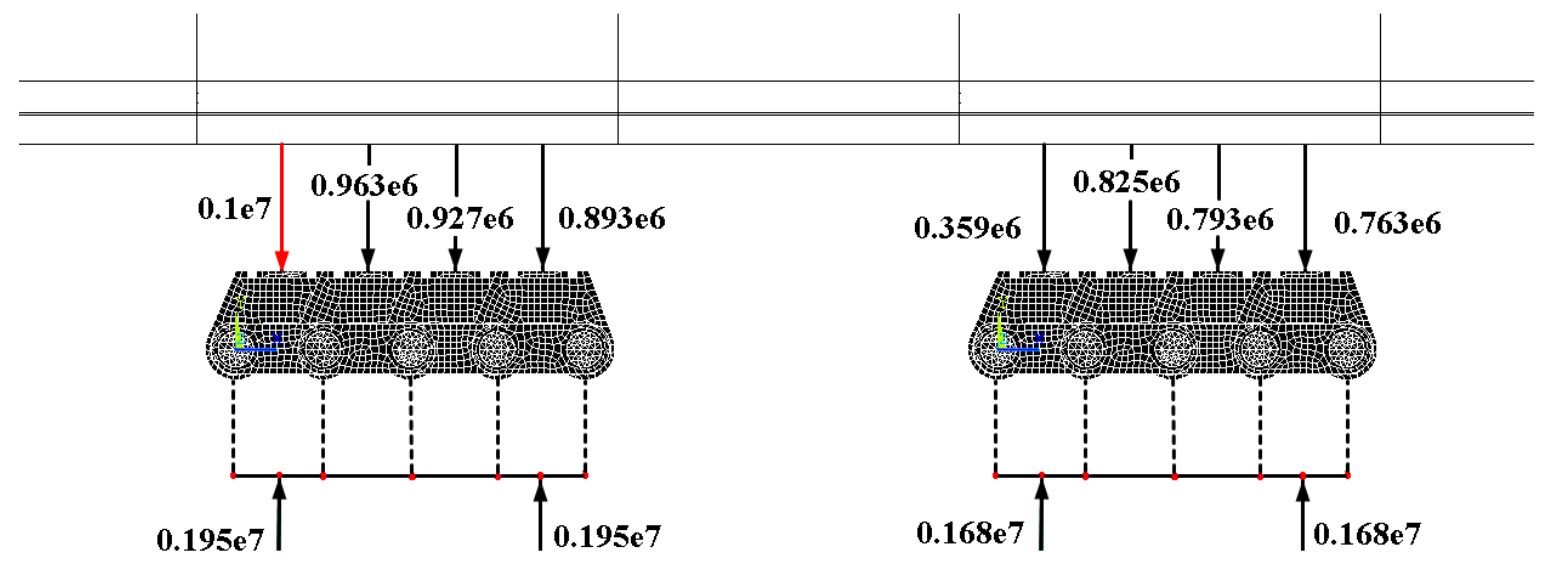

(b)

$180 \mathrm{~m}$. of bridge launched

Launching direction

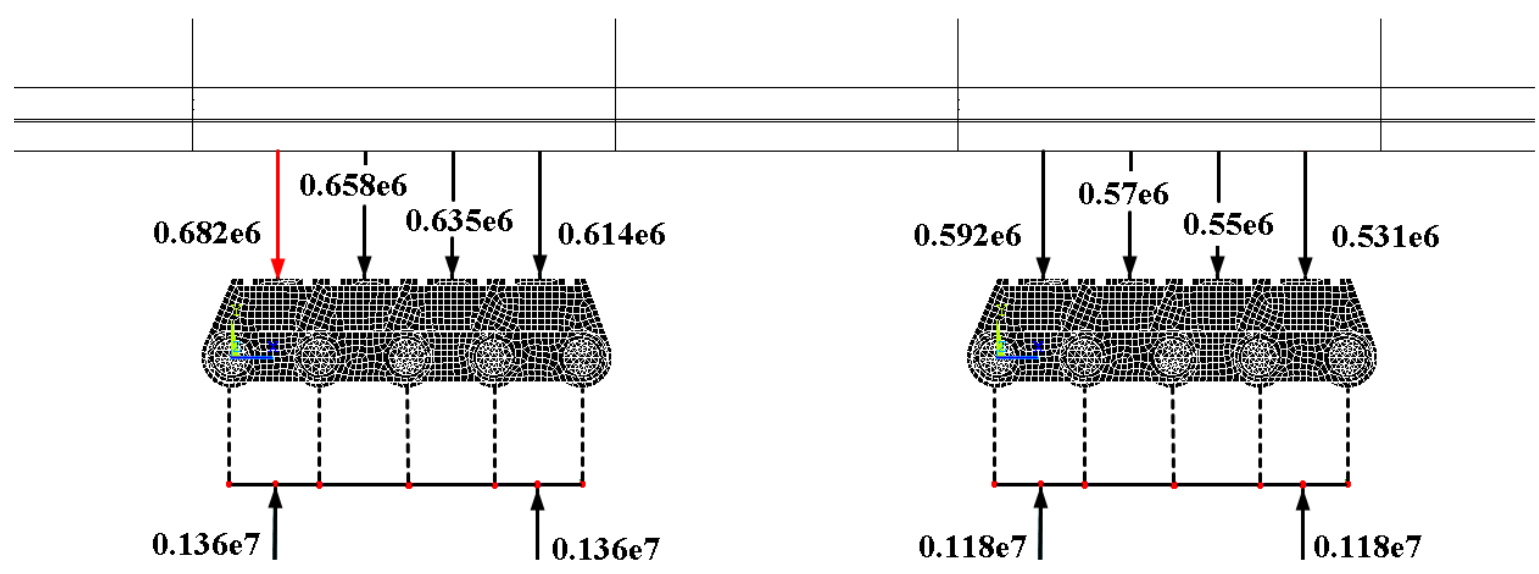

(c) 
$220 \mathrm{~m}$. of bridge launched

Launching direction

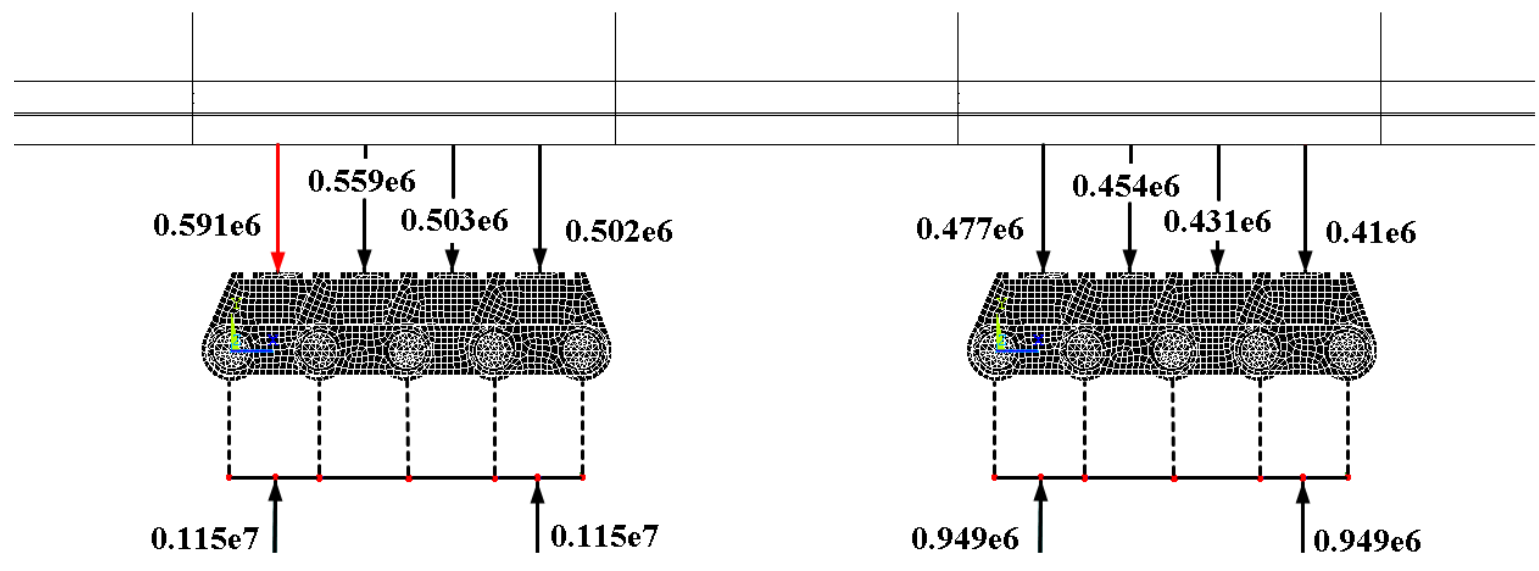

(d)

Fig. 10. Non-uniform distribution of the normal load over the DCACLM device for different lengths of bridge launched: (a) 120 m.; (b) 160 m.; (c) 180 m.; (d) $220 \mathrm{~m}$.

\section{Conclusions}

332 A numerical study of the structural interaction between the bridge structure and a new launching device is presented in this paper. This study was carried out using the sub-structuring technique with which two complex numerical models are reduced to a simplified numerical one. The numerical model used takes into account several phases of launching in the construction process, as well as three different positions of the new launching device.

337 The results obtained for each case studied are shown in Table 2.

338 Table 2. Maximum values of the reaction force.

\section{PARALLEL DISPOSITION}

$\begin{array}{ccc}\begin{array}{c}\text { External } \\ \text { device opposite } \\ \text { internal one }\end{array} & \begin{array}{c}\text { External device } \\ \text { behind internal }\end{array} & \text { SERIAL } \\ \text { DISPOSITION } \\ \text { one }\end{array}$

\section{Maximum Force reaction} in each support link [N]

$3.42 \cdot 10^{6} \quad 3.26 \cdot 10^{6} \quad 2.09 \cdot 10^{6}$


Maximum force reaction in each device DCACLM [N]

$10.9 \cdot 10^{6} \quad 11.3 \cdot 10^{6} \quad 8 \cdot 10^{6}$

The proposed numerical model by sub-structuring and the constraint equations were developed using finite element software, ANSYS Academic Research APDL. The main conclusions obtained in this work are as follows:

- A very complicated problem which consists of two non linear numerical models can be simplified to a global numerical model using the sub-structuring technique. This technique enables the reduction of computational power and time.

- Three arrangements of the DCACLM launching devices under the bridge structure were studied. The comparison shows that the series arrangement is the best for the DCACLM launching devices. In order to reduce the maximum stress in resistant elements, the DCACLM launching devices should be in series under the webs of the bridges.

- The normal load on the launching device is distributed on four support links. The numerical model developed in this paper showed the non uniform distribution of the normal load among the supports. This fact is due to the low local stiffness of the bridge structure. The distribution of the normal load on the support links of the DCACLM launching devices was found in this finite element analysis only for the series arrangement which was chosen as the best arrangement. The same procedure was used to obtain the distribution of the vertical force in four different phases of the launching process. In this way, an approach to the evolution of the normal load distribution was obtained, together with the necessary reaction to compensate the bridge structure deformation.

\section{Acknowledgements}

The authors express deep gratitude to the GICONSIME and GITECO Research Groups at Oviedo University and Cantabria University, respectively, for their useful assistance and the anonymous comments and suggestions of the reviewers. This work was partially financed with FEDER funds by the Spanish Ministry of Science and Innovation through the Research Project BIA2012-31609 and the Gijon City Council through the SV-13-GIJON-1.7 project. We would also like to thank Swanson Analysis Inc. for the use of the ANSYS University research program and Workbench simulation environment. Finally, we would like to acknowledge the help of the Spanish Ministry of Economics and Competitiveness through the Research Project ALCANZA, IPT-380000-2010-012 INNPACTO program.

\section{References}


[1] Leonhardt F, Bauer W. The bridge across the Caroni River from Puerto Ordaz to San Felix in Venezuela. Trends 1964;31:27-29.

[2] Bernabeu Larena J. Evolución tipológica y estética de los puentes mixtos en Europa. Doctoral Thesis. Madrid Polytechnic University; Spain. 2004.

[3] Rosignoli M. Bridge Launching. Italy. Thomas Telford. 2002.

[4] Rosignoli M. Bridge erection machines. USA. HNTB Corp. 2012

[5] Millanes Mato F, Pascual Santos J, Ortega Cornejo M. "Arroyo las Piedras" viaduct: the first composite steel-concrete high speed railway bridge in Spain. Hormigón y Acero 2007; 243: 5-38.

[6] VSL International LTD. The incremental launching method in prestressed concrete bridge construction. Schwarzenburg. Gerber AG. 1977.

[7] Manterola Armisén J, Siegrist Fernández C, Gil Ginés MA. Bridges. UP Madrid. ETSICCP 2000.

[8] Djelosevic M., Gajic V., Petrovic D., Bizic M. Identification of local stress parameters influencing the optimum design of box girders. Engineering Structures 2012, 40: 299316.

[9] Hassanein M.F., Kharoob O.F. Behavior of bridge girders with corrugated webs: (II) Shear strength and design. Engineering Structures, In Press, Corrected Proof, Available online 17 June 2013.

[10] Maiorana E, Pellegrino C, Modena C. Linear buckling analysis of unstiffened plates subjected to both patch load and bending moment. Engineering Structures 2008; 30: 3731-3738.

[11] Granath P. Distribution of support reaction against a steel girder on a launching shoe. Journal of Constructional Steel Research 1998: 47 (3):245-270.

[12] International Patent WO2013/001114 A1. Device for continuous movement of structures. 2013

[13] Li ZX, Chan THT, Yo Y, Sun ZH. Concurrent multi-scale modeling of civil infrastructures for analyses on structural deterioration. Finite Elements in Analysis and Design 2009; 45:782-794.

[14] Somja H, Ville de Goyet V. A new strategy for analysis of erection stages including an efficient method for creep analysis. Engineering Structures 2000; 30:2871-2883. 
[15] Cruz P, Mari A, Roca P. Non linear time-dependent analysis of segmentally constructed structures. ASCE Journal of Structural Engineering 1998; 124:278-287.

[16] Popp K, Schiehlen W. Ground vehicle dynamics. Germany. Springer 2010.

[17] Muro T, O'Brien J. Terramechanics: Land locomotion mechanics. Taylor and Francis 2004.

[18] Mari A. Numerical simulation of the segmental construction of three dimensional concrete frames. Engineering Structures 2000; 22:585-596.

[19] del Coz Diaz JJ, Garcia Nieto PJ, Fernández Rico M, Suárez Sierra JL. Non-linear analysis of the tubular 'heart' joint by FEM and experimental validation. Journal of Constructional Steel Research 2007; 63(8): 1077-1090.

[20] Betegón Biempica C, del Coz Díaz JJ, García Nieto PJ, Peñuelas Sánchez I. Nonlinear analysis of residual stresses in a rail manufacturing process by FEM. Applied Mathematical Modelling 2009; 33(1):34-53.

[21] Bathe KJ. Finite element procedures. New Jersey: Prentice-Hall 1998.

[22] Moaveni S. Finite element analysis: theory and applications with ANSYS. New York: Prentice-Hall 2007.

[23] Madenci E, Guven I. The finite element method and applications in engineering using ANSYS. New York. Springer 2007.

[24] Reddy JN. An introduction to nonlinear finite element analysis. Oxford University Press, New York 2004.

[25] del Coz Díaz JJ, García Nieto PJ, Betegón Biempica C, Fernández Rougeot G. Nonlinear analysis of unbolted base plates by the FEM and experimental validation. Thin-Walled Structures 2006; 44(5): 529-541.

[26] del Coz Díaz JJ, García Nieto PJ, Vilán Vilán JA, Suárez Sierra JL. Non-linear buckling analysis of a self-weighted metallic roof by FEM. Mathematical and Computer Modelling 2010; 51(3-4): 216-228. 